\title{
THREE-DIMENSIONAL MORPHODYNAMIC MODEL TO SANDY BEACH WITH NON-ERODED HARD BOTTOM
}

\author{
Yukihiko Hasegawa ${ }^{1}$, Masamitsu Kuroiwa $^{2}$,Yuhei Matsubara ${ }^{3}$ \\ Yasushi Icimura ${ }^{4}$ and Yoshiyuki Nagaishi ${ }^{5}$
}

\begin{abstract}
The objective of study is to develop a coastal area model for sandy beach with shore reef such as non-eroded hard bottom. The morphodynamics with exposure and bury of the shore reef are reproduced by advection and diffusion model for suspended sediment concentration. Firstly, model tests associated with sandy beaches with a detached breakwater and groins were carried out in order to investigate the performance of the presented model. Secondly, the presented model was applied to a filed site with both shore reef and sandy beach, the applicability of the model was investigated and discussed.
\end{abstract}

Keywords: morphodynamics; sediment transport; beach evolution model;shore-reef

\section{INTRODCUTION}

Many morphodynamic models for predicting three-dimensional (3D) deformation of sandy beach, which is so called "Coastal Area Model", have been proposed (e.g. Watanabe et al.,1986; de Vriend et al,1993; Johnson et al.,1994; Zyserman et al., 2002; Lesser et al.,2004; Kuroiwa et al.,2004). The predictive $3 \mathrm{D}$ models are very useful to predict beach evolution due to construction of coastal structures such as detached breakwaters, groins and so on. In general, actual sandy beaches consist of various grain size, or include non-eroded hard bottom such as shore reef. The actual mophodynamics are extremely complex. Therefore, the development and modification of the coastal area model have been still proceeded. Some models for considering the effect of grain size of bed material were proposed(e.g. Kuroiwa et al.,2006), and for sandy beach with non-eroded hard bottom have also presented(e.g. Ikeno et al.,2004; Hans et al.,2005).

Sakenotsu fishing port, Tottori, Japan, facing the Sea of Japan, has been suffered from sedimentation at the entrance and channel of the fishery port. Sakenotsu fishing port is surrounded shore reef, which is non-eroded hard bottom, and adjacent to Mizushiri sandy beach Therefore, the phenomena of the sediment transport due to waves and nearshore currents may be influenced by the existence of the shore reef. Although several countermeasures such as the extension of offshore breakwaters have been performed, the dredging work of bed material that has accumulated in the harbor entrance still has been carrying out. The accretion mechanism should be clarified and some new countermeasures against the sedimentation problem are needed. In order to propose some countermeasures, a reliable 3D morphodynamic model considering the influence of the hard bottom, which is the phenomena of the exposure and burying of the hard bottom due to drifting sand, is needed.

The purpose of this study is to develop a numerical model for predicting three-dimensional beach evolution to sandy beach with hard sea bottom such as shore reef. In this paper, at first, in order to investigate the influence of the hard bottom and the performance of the presented model, some model tests were carried out. Furthermore, in order to investigate the applicability of the model, the developed model was applied to the 3D morphodynamics around Sakenotsu fishing port.

\section{NUMERICAL MODEL}

The presented numerical model for predicting bottom topographical changes consists of three modules, as shown in Fig.1. In the model, the coastal area model using Q-3D nearshore current model, proposed by Kuroiwa et al.(2010) was modified so as to be considered the influence of sea bottom with non-eroded hard bottom such as shore reef.

\section{Wave and nearshore current modules}

The wave and nearshore current modules are based on the hybrid model presented by Kuroiwa et al.(2006). The wave field is determined by the energy balance equation presented by Mase(2001). The nearshore current field is determined by the depth-averaged $(2 \mathrm{DH})$ mode or quasi-3D $(\mathrm{Q}-3 \mathrm{D})$ mode in

\footnotetext{
${ }^{1}$ Tottori City Government Office, 116,Shoutoku-chou,Tottori,680-8571,Japan

2 Department of Civil Engineering, Tottori University, 4-101,Koyama, Tottori,680-8552,Japan

${ }^{3}$ Department of Civil Engineering, Tottori University, 4-101,Koyama, Tottori,680-8552,Japan

${ }^{4}$ Mikuniya Corporation, 3-1-10, Naniwa-ku, Saiwai-chou, Osaka, 556-0021,Japan

${ }^{5}$ Tottori City Government Office, 116,Shoutoku-chou,Tottori,680-8571,Japan
} 
the hybrid model, according to wave condition and prediction period. The Q-3D is selected under stormy waves.



Figure 1. Flowchart of the presented morphodynamic model.

\section{Sediment transport module}

The total sediment transport takes account for the bed and suspended load. In the suspended load model, the advection diffusion model for the suspended sediment concentration was adapted to take account of exposing the hard bottom such as shore reef due to picking up of sand material and burying the shore reef due to settling of suspended sediment. Moreover, the estimation of the bed load that considered the sand layer thickness over the hard bottom, was according to Ikeno et al.(2002).

The water depth change was computed by the continuity equation, as follows:

$$
\frac{\partial h}{\partial t}=\frac{1}{1-\lambda}\left(-Q_{s}\right)+\frac{1}{1-\lambda}\left\{\frac{\partial}{\partial x}\left(q_{b x}+\varepsilon_{s}\left|q_{b x}\right| \frac{\partial h}{\partial x}\right)+\frac{\partial}{\partial y}\left(q_{b y}+\varepsilon_{s}\left|q_{b y}\right| \frac{\partial h}{\partial y}\right)\right\}
$$

where $x$ is the shoreward axis from offshore. $y$ is the alongshore axis. $h$ is the water depth. $q_{b x}$ and $q_{b y}$ are the bed loads, which are estimated based on Watanabe model(1986). $\varepsilon_{s}$ is the dimensionless coefficient that represents the effect of beach slope. $Q_{s}$ is the difference between the upward sediment flux $F_{z}$ and the downward flux $w_{f} C$, as computed by Sawaragi model(1984). $Q_{s}$ is given by

$$
Q_{s}=F_{z}-w_{f} C
$$


where, $w_{f}$ is the settling velocity of sand. $C$ is the suspended sediment concentration, which determined by solving the following advection diffusion equation, as given by,

$$
\frac{\partial C}{\partial t}+U \frac{\partial C}{\partial x}+V \frac{\partial C}{\partial y}=\frac{\partial}{\partial x}\left(K_{x} \frac{\partial C}{\partial x}\right)+\frac{\partial}{\partial y}\left(K_{y} \frac{\partial C}{\partial y}\right)+\frac{Q_{s}}{\bar{\eta}+h}
$$

where $K_{x}$ and $K_{y}$ are the diffusion coefficients. $U$ and $V$ are the depth-averaged steady current velocities.

The bed load is determined by the sum of the wave and nearshore current components. The total bed load considers the effect of the sand layer thickness $h_{s d}$ on the hard bottom. The sand layer thickness $h_{s d}$ is defined as shown in Fig.2. The dimensionless coefficient $A_{s d}$ associated with the rate of $h_{s d}$ and ripple height $\zeta$ is added into the total bed load, as given by

$$
\begin{aligned}
& \overrightarrow{q_{b}}=A_{s d}\left(\overrightarrow{q_{w}}+\overrightarrow{q_{c}}\right) \\
& A_{s d}=h_{s d} /(\zeta / 2)
\end{aligned}
$$

These are estimated by

$$
\begin{aligned}
& \overrightarrow{q_{w}}=A_{w}\left\{\left(u_{*}\right)^{2}-\left(u_{*_{c}}\right)^{2}\right\} \overrightarrow{u_{w}} / g \\
& \overrightarrow{q_{c}}=A_{c}\left\{\left(u_{*}\right)^{2}-\left(u_{*_{c}}\right)^{2}\right\} \overrightarrow{U_{c}} / g
\end{aligned}
$$

where $A_{w}$ and $A_{c}$ are dimensionless coefficients. $u *$ is the friction velocity. $u_{*}$ is the critical friction velocity. $\vec{U}_{c}$ is the steady current vector at the sea bottom. In case of the $2 \mathrm{DH}$ mode, the bed load due to nearshore current velocity at sea bottom is determined. The coefficients $A_{w}$ and $A_{c}$ are given by a function of the median diameter $d_{50}$ (Shimizu et al., 1996) .

In Equations (4) and (5), as $h_{s d}>\zeta / 2, A_{s d}=1.0$, on the other hand, as $h_{s d}=0, A_{s d}=0$, namely the total bed load $q_{b x}$ and $q_{b y}$ are equal to 0 .

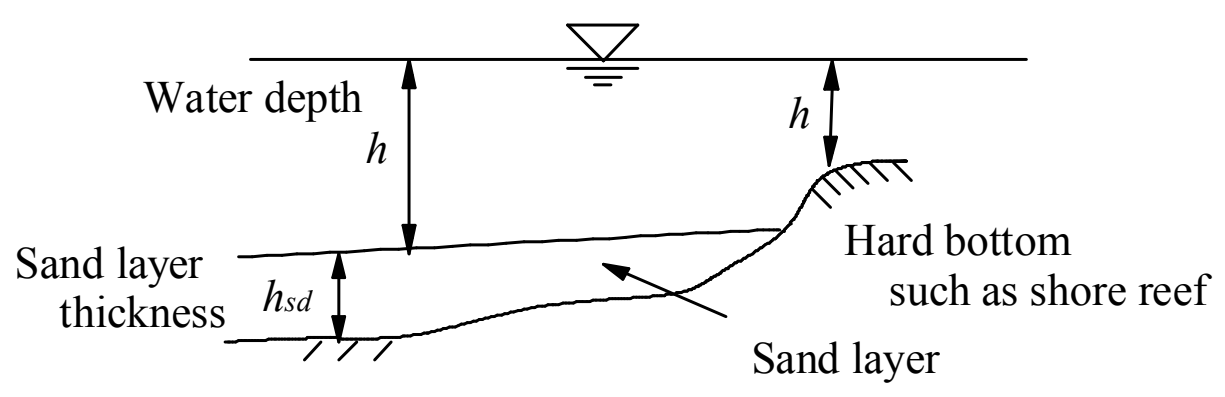

Figure 2. Definition of hard bottom and sand layer thickness.

\section{MODEL TESTS - COMPARISON OF COMPUTATIONS WITH AND WITHOUT SHORE REEF}

\section{Model test for shore reef beach with a detached breakwater}

A model test associated with a detached breakwater as shown in Fig. 3 was designed to describe the performance of the presented model. The computational domain was set to an area of $500 \mathrm{~m}$ in the cross-shore direction and $600 \mathrm{~m}$ in the alongshore direction. The beach slope was $1 / 50$. In the area, a detached breakwater with the length of $100 \mathrm{~m}$ was set at the water depth of $2.5 \mathrm{~m}$. In this model test, exposed hard bottom was set in a half area of the computational domain, in order to investigate the influence of the hard bottom, as shown in Fig.3. At first, under wave height of $2 \mathrm{~m}$, bottom topographical change after 20 days was simulated without hard bottom as shown in Fig. 4. The computed results show the generation of typical symmetric circulation pattern and deposition behind 
the detached breakwater. Fig. 5 shows computed results with hard bottom. It is found that the computed nearshore current field behind the detached breakwater is asymmetric current pattern, and the computed depth contour.

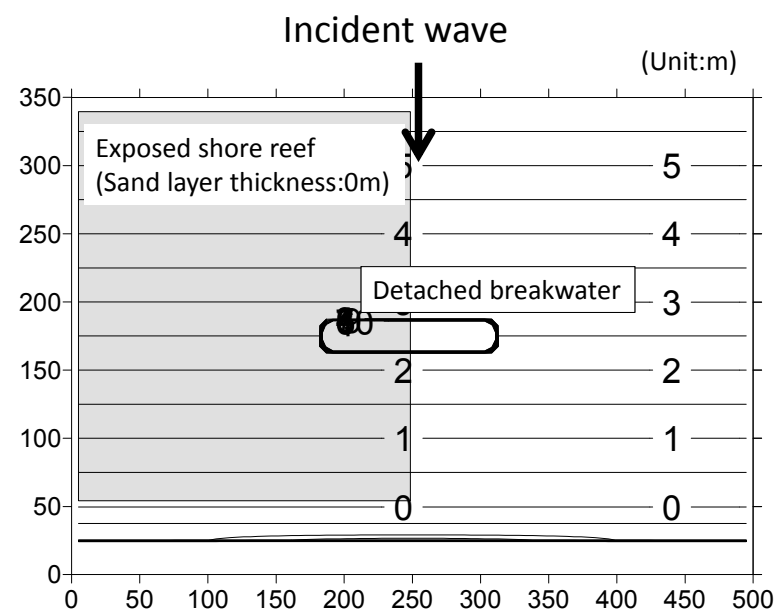

Significant

wave height : $\mathrm{Hs}=2.0 \mathrm{~m}$

wave period: $T s=8.0 \mathrm{~s}$

Wave direction: normal direction

Figure 3. Initial bathymetry of a sandy beach with exposed hard bottom and a detached breakwater.

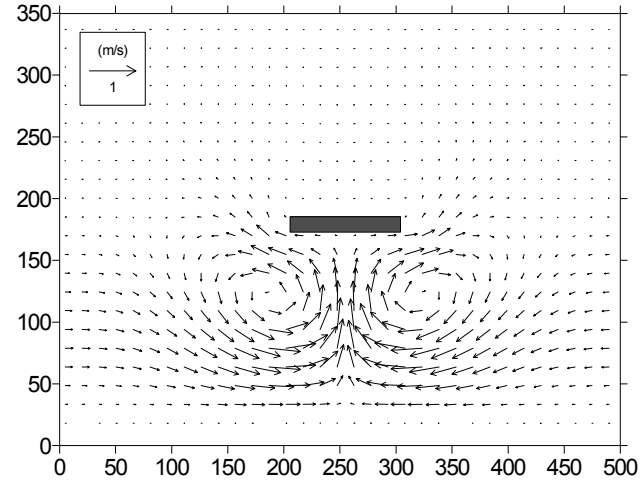

(a) nearshore current field

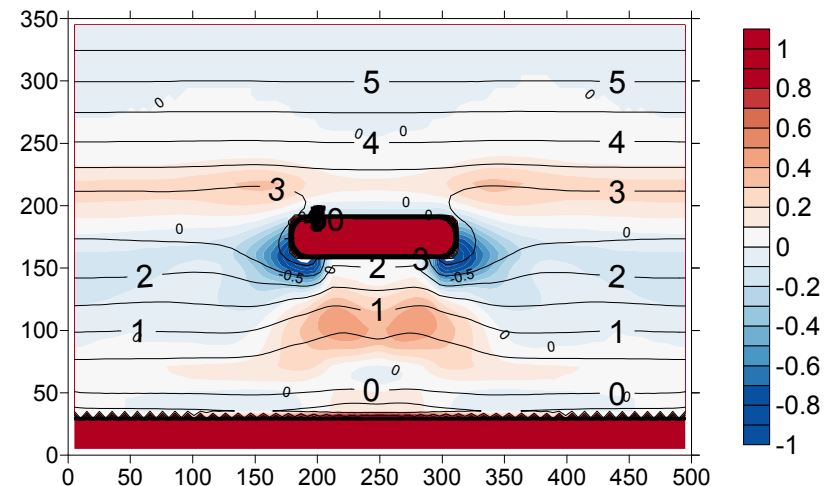

(b) bathymetry change

Figure 4. Computed result for a detached breakwater without exposed hard bottom.

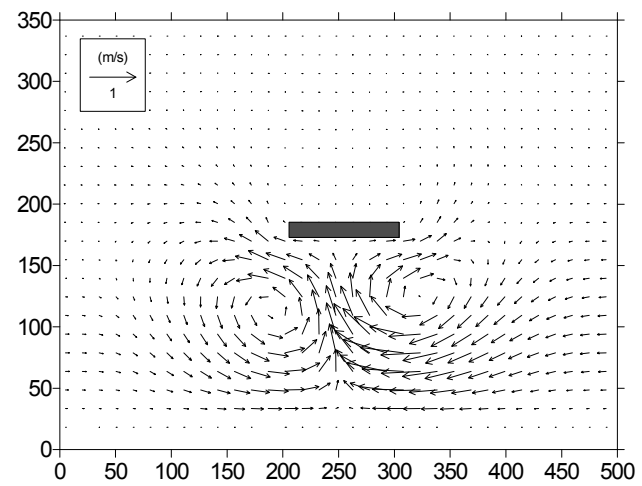

(a) nearshore current field

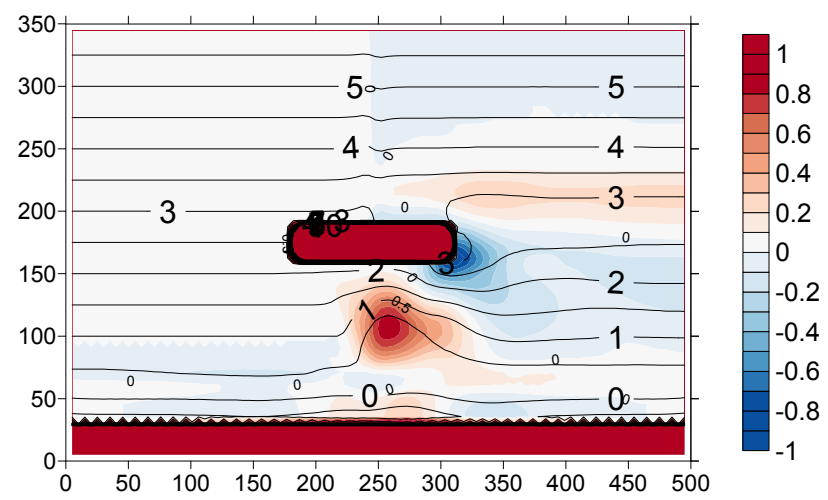

(b) bathymetry change

Figure 5. Computed result for with exposed hard bottom. 


\title{
Model test for a pocket beach
}

The model was applied to a pocket beach with exposed shore reef (A) and (B), situated between two groins as shown in Fig. 6. The computational domain was set to an area of $500 \mathrm{~m}$ in the crossshore direction and $600 \mathrm{~m}$ in the alongshore direction. The input significant wave height and period were $1.5 \mathrm{~m}$ and $7.0 \mathrm{~s}$. The grid spacing $\Delta x$ and $\Delta y$ in the computations were set to $10 \mathrm{~m}$. The median diameter $d_{50}$ was $0.2 \mathrm{~mm}$.

The bathymetry changes without and with hard bottom were computed, as shown in Fig. 7 and 8 , respectively. In each case, firstly, the bathymetry change after 5days under oblique wave with the direction of +20 degrees was computed, and then, the bathymetry change after 10 days was computed under -20 degrees. In case without hard bottom, the erosion was occurred in the upstream area of longshore current, and then the accretion in the downstream area, as shown in Figure 7(a). These sea bottom changes normally were generated in sandy beaches under oblique waves. Figures 8(a) and (b) show the computed bathymetry changes with hard bottom (A) and (B). From Figure 8(a), it can be seen that the sea bottom was eroded around the $\operatorname{rock}(\mathrm{A})$, on the other hand, the deposition was occurred around the $\operatorname{rock}(\mathrm{B})$. The deposition over the $\operatorname{rock}(\mathrm{B})$ is due to the settling of suspended load. After changing wave direction, the left side of the $\operatorname{rock}(\mathrm{B})$ was eroded because there was no supply of sediment from the area(B). It is found that the existence of the exposed rock influences on the beach evolution for sandy beach.

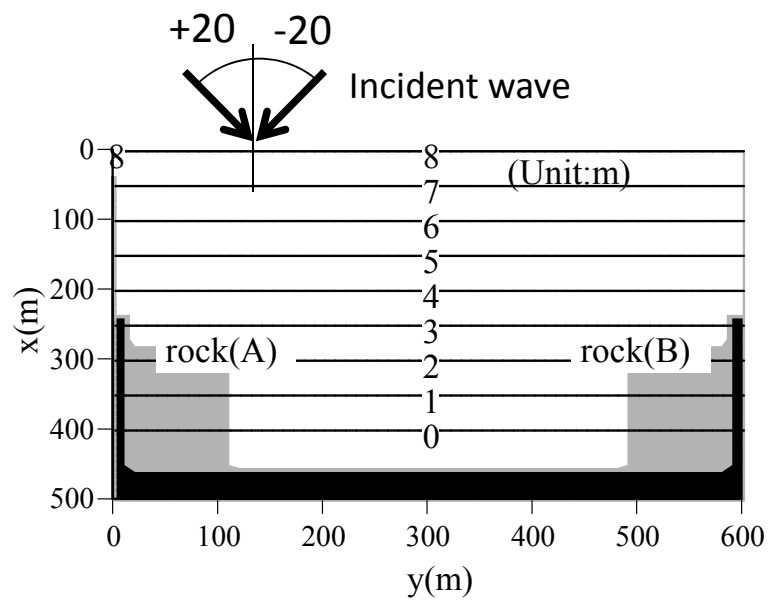

\author{
Significant \\ wave height : $\mathrm{Hs}=1.5 \mathrm{~m}$ \\ wave period: $\mathrm{Ts}=8.0 \mathrm{~s}$ \\ Wave direction: $+20,-20$ degrees
}

Figure 6. Initial bathymetry for a pocket beach with exposed hard battom.

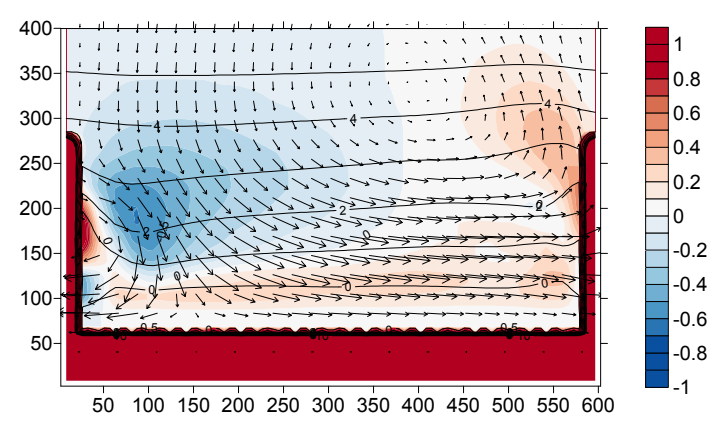

(a) Bathymetry changer after 5 days $(+20)$

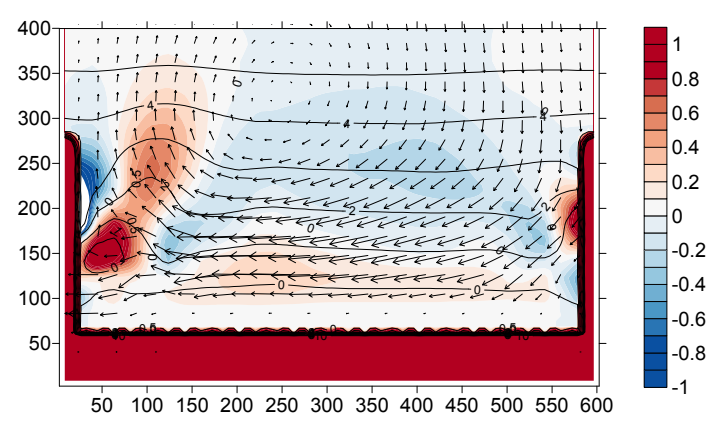

(b) Bathymetry changer after 10days(-20)

Figure 7. Computed results for morphodynamic of a pocket beach without non-eroded hard bottom. 




(a) Bathymetry changer after 5days $(+20)$

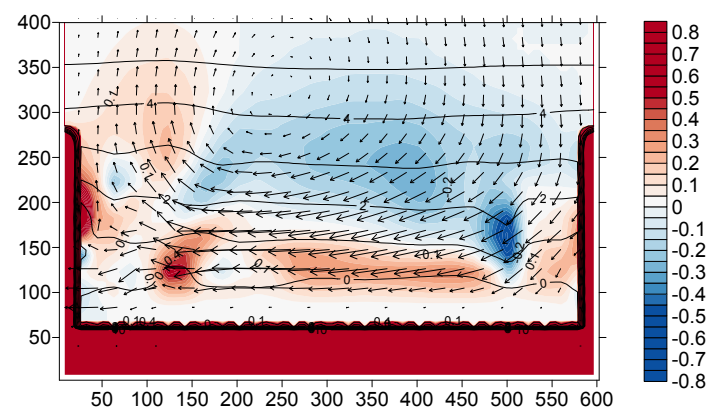

(b) Bathymetry changer after 10days(-20)

Figure 8 Computed results for morphodynamic of a pocket beach with non-eroded hard bottom.

\section{MODEL APPLICATION TO FIELD OBSERVATION}

\section{Field Observation around Sakenotsu Fishing Port}

Sakenotsu fishery port is located on the eastern part of Tottori, facing the Sea of Japan. Figure 9 shows the bathymetry around the fishery port. In this figure, the area of gray color represents the shore reef area with exposed rock. The sand drift phenomenon around the port is remarkable because of closing to Mizushiri sandy beach. Thus, the sedimentation of the entrance of the fishery port often occurs. The field observation has been performed from February 2009 to March 2011. In the field observation, the bottom soundings were carried out for 5 times in Feb. 2009, Mar. 2009, May 2010, Nov. 2010 and Feb. 2011.

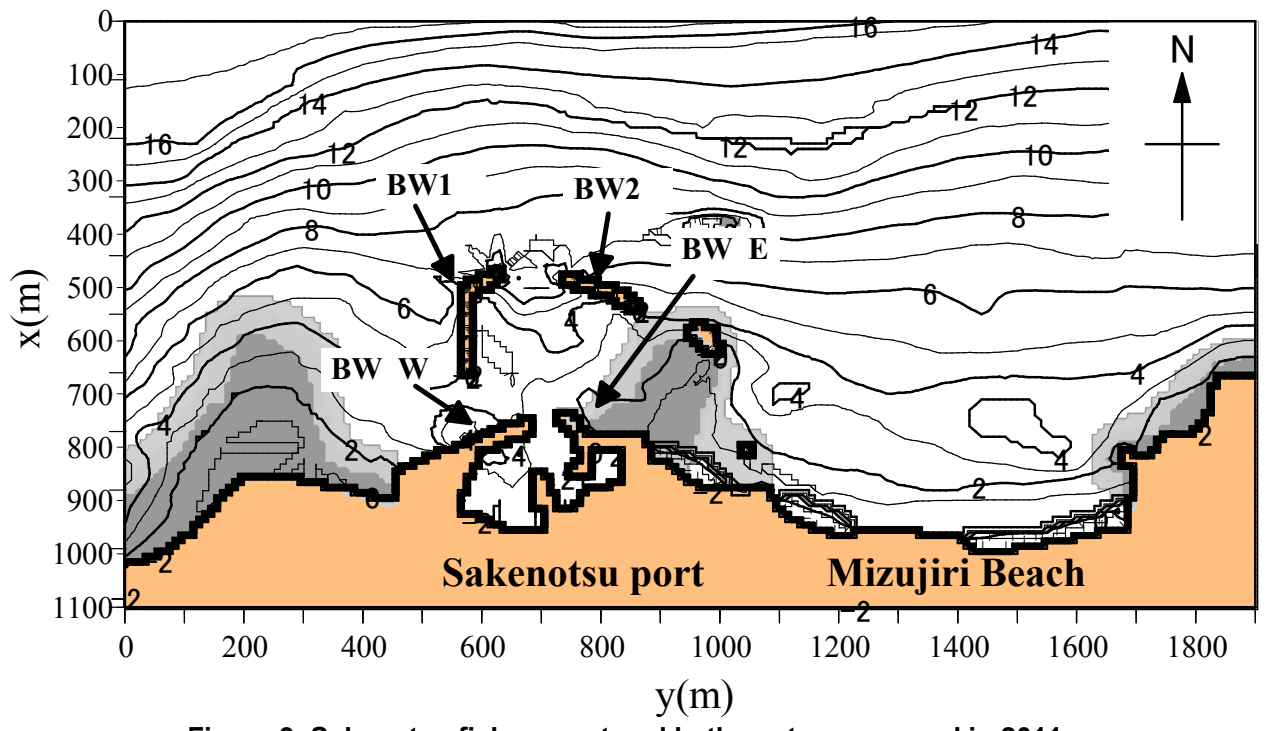

Figure 9. Sakenotsu fishery port and bathymetry measured in 2011.

In this study, the sea bottom topographical changes from 27 Feb. to 31 Mar. in 2009 (Case1), and 31 May to 13 Nov. in 2010 (Case2), were adapted in order to verify the presented numerical model. Figures 10 (a) and (b) show the sounding results with erosion/sedimentation plot for Case 1 and Case2, respectively. In March 2009, the water depth in the range from $y=200 \mathrm{~m}$ to $1200 \mathrm{~m}$ was only measured. The depth contour in the range from $y=1200 \mathrm{~m}$ to $1800 \mathrm{~m}$ was made using the survey result in May 2010. From Fig.10(b), it can be seen that the deposition was remarkably occurred behind the offshore breakwater BW1. Every winter season, although the rate of deposition in the offshore breakwaters BW1 and BW2 is actually large, the deposition in 2009 is smaller than that in the case of survey result in 2010 because the dredging was conducted before the sounding survey on 31 March 2009. 




(a) Case1 (from 27 Feb. to 31 Mar. in 2009)

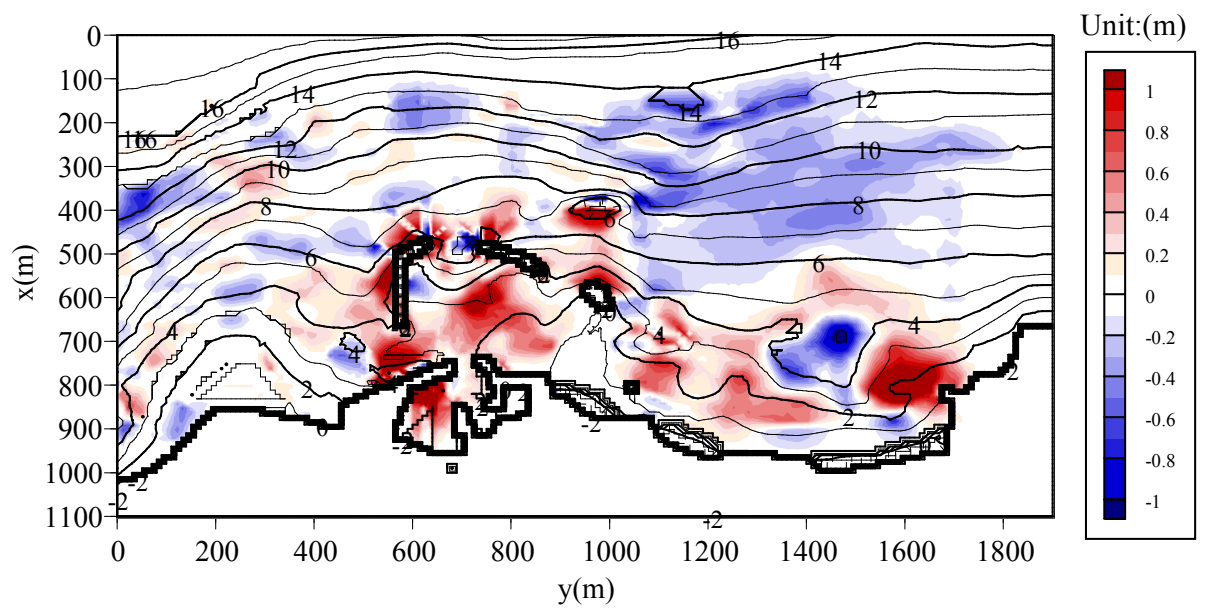

(b) Case2 (from 31 May to 13 Nov. in 2010)

Figure 10. Sounding survey results in 1010 and 2011.

\section{Computational Conditions}

The computational domain was set to an area of $1100 \mathrm{~m}$ in the cross-shore direction and $1900 \mathrm{~m}$ in the alongshore direction, as shown in Fig.11. The thickness of sand layer at each area was assumed as shown in this figure. In this study, two cases, which are the survey results of beach evolution from 27 Feb. to 31 March in 2009 (Case1) and from 31 May to 13 November in 2010 (Case2), were employed to verify the presented model. The wave conditions at offshore boundary, which are the significant wave height and period, were arranged from the results observed at the water depth of $30 \mathrm{~m}$ in Tottori Port. The wave direction was set using the wave data observed at the water depth of $5.5 \mathrm{~m}$ in the Mizushiri sandy beach.

Figs. 12 and 13 show the modeled wave time variations for Case1 and 2, respectively. The wave height less than $1.0 \mathrm{~m}$ was omitted because the waves do not remarkably contribute the bottom topographical changes. The input wave data sets for Case 1 and 2 are shown in Tables 1 and 2,respectively. 


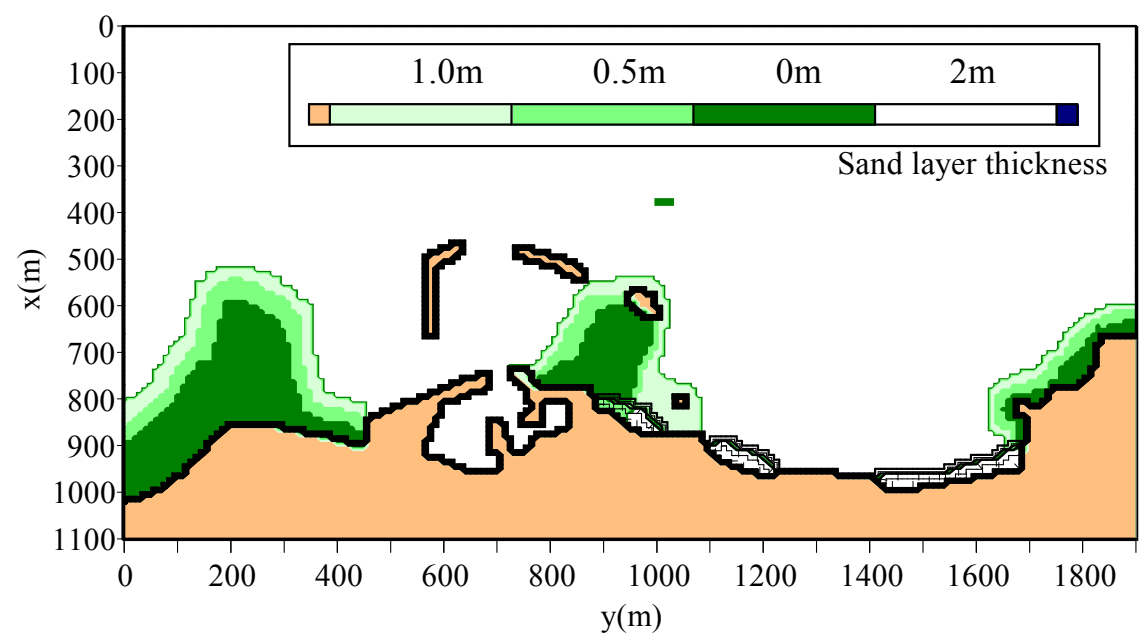

Figure 11. Computational domain and definition of sand layer thichness

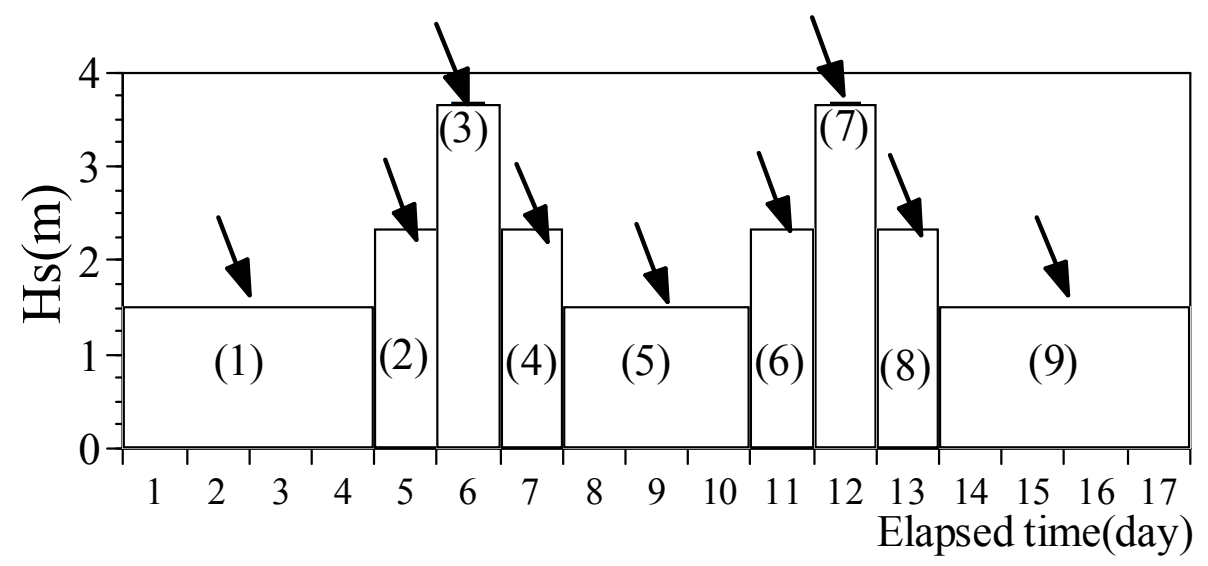

Figure 12. Modeled time variation of wave height for Case1 (from 27 Feb. to 31 Mar. in 2009)

\begin{tabular}{|c|c|c|c|c|c|c|c|}
\hline Step & $\mathrm{Hs}(\mathrm{m})$ & $\mathrm{Ts}(\mathrm{s})$ & Direction & Step & $\mathrm{Hs}(\mathrm{m})$ & $\mathrm{Ts}(\mathrm{s})$ & Direction \\
\hline $\begin{array}{l}(1),(5),(9) \\
\end{array}$ & $\overline{1.5}$ & $\overline{6.9}$ & 14.9(NNW) & $(2),(4),(6)(8)$ & 2.5 & $\overline{7.7}$ & 24.7(NNW) \\
\hline (3),(7) & 3.7 & 9.7 & 15.1(NNW) & & 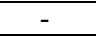 & - & \\
\hline
\end{tabular}

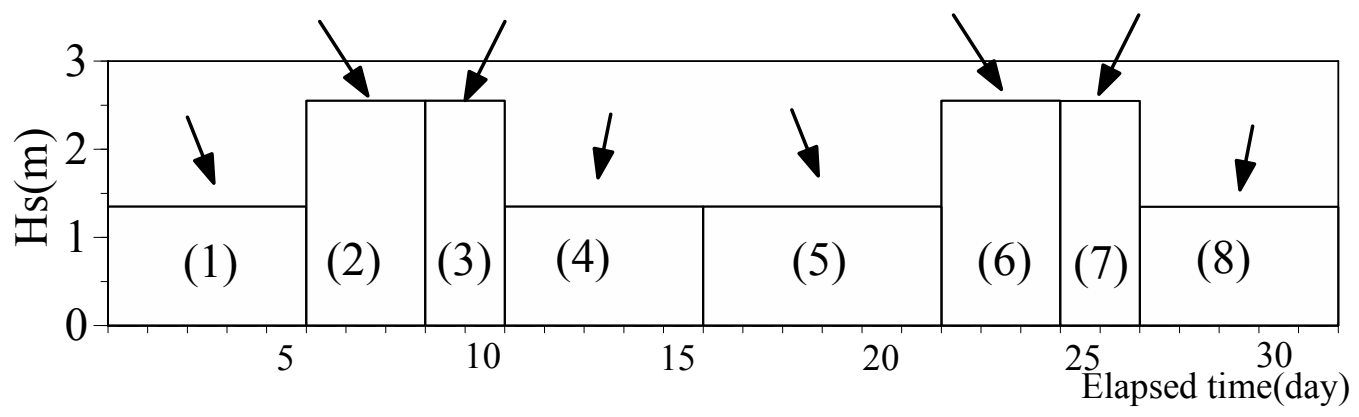

Figure 13. Modeled time variation of wave height for Case2 (from 31 May to 13 Nov. in 2010) 


\begin{tabular}{|c|c|c|c|c|c|c|c|}
\hline \multicolumn{7}{|c|}{ Table 2. Significant wave height, period and mean wave direction for Case1 } \\
(from 31, May to 13, Nov., in 2010). \\
\hline Step & $\mathrm{Hs}(\mathrm{m})$ & $\mathrm{Ts}(\mathrm{s})$ & Direction & Step & $\mathrm{Hs}(\mathrm{m})$ & $\mathrm{Ts}(\mathrm{s})$ & Direction \\
\hline \hline$(1),(5)$ & 1.4 & 6.8 & $19.0(\mathrm{NNW})$ & $(2),(6)$ & 2.5 & 7.7 & $24.7(\mathrm{NNW})$ \\
\hline$(4),(8)$ & 1.4 & 6.5 & $-15.5(\mathrm{NNE})$ & $(3),(7)$ & 2.5 & 7.8 & $-18.0(\mathrm{NNE})$ \\
\hline
\end{tabular}

\section{Computed results}

Figures 14 (a) and (b) show an example of computed nearshore current field and erosion/deposition plot represented by the difference between the initial and computed final bathymetry, regarding with Case1. The sounding result on 27 Feb 2009 was used as the initial bathymetry. It is found that the deposition between BW1 and BW-W is reproduced.

Figure 15 shows the computed results for Case2, by using the survey result on 31 May 2010 as the initial bathymetry. From Fig. 15(b), it is found that the rate of the deposition behind the breakwater BW2 of the presented model is smaller than that of the field observation as shown in Fig. 10(b). On the other hand, the erosion rate in the vicinity of the exposed rock area in the range from $y=0 \mathrm{~m}$ to $400 \mathrm{~m}$ was overestimated.

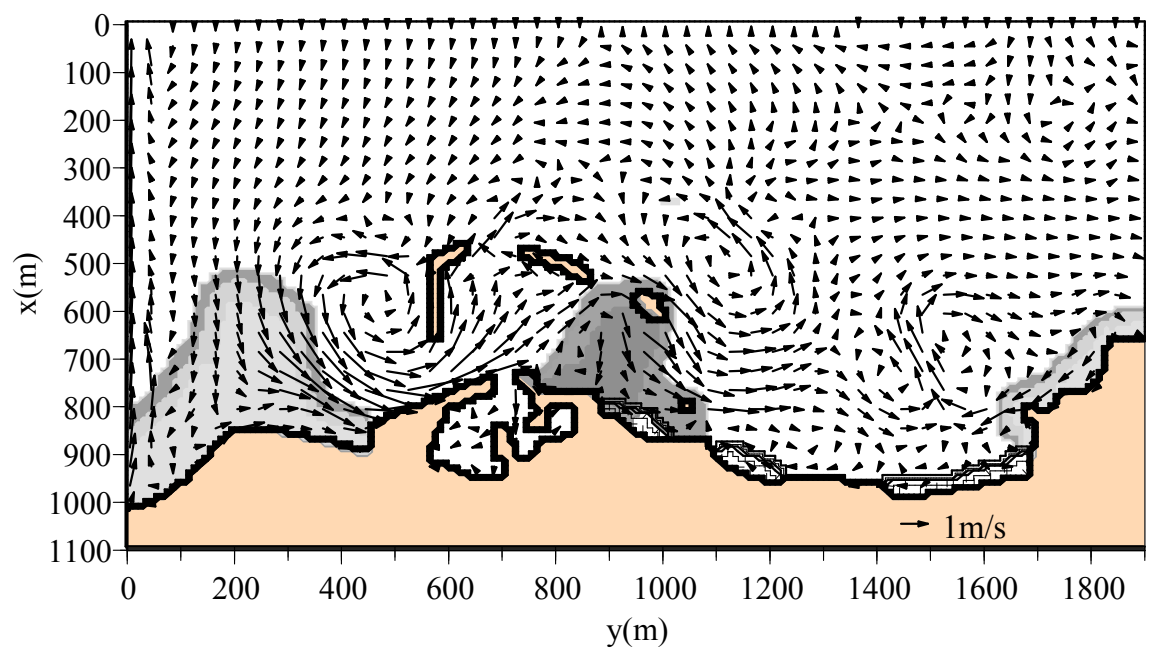

(a) Nearshore current field for step(3)(NNW)

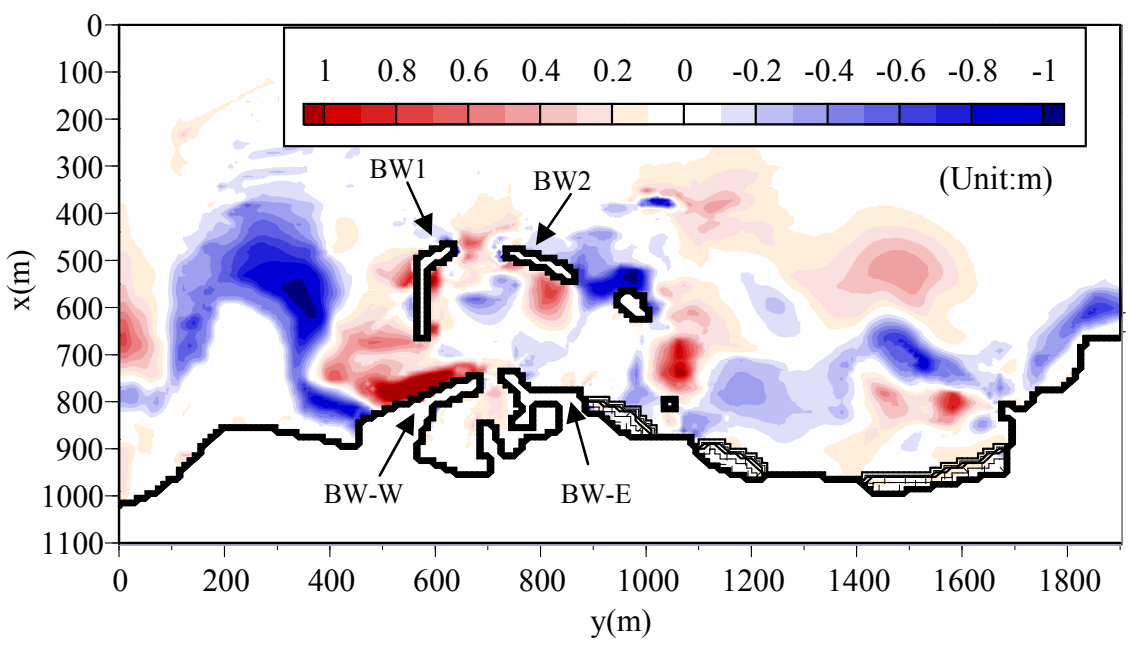

(b) Computed erosion/deposition plot

Figure 14. Computed results for Case1 
From the results mentioned above, it was found that the developed model could qualitatively reproduce 3D topographical changes involving the influence of the shore reef. However, the changes in the thickness of sand layer could not represent sufficiently, because of the lack of detailed field data regarding with the actual thickness of sand layer.

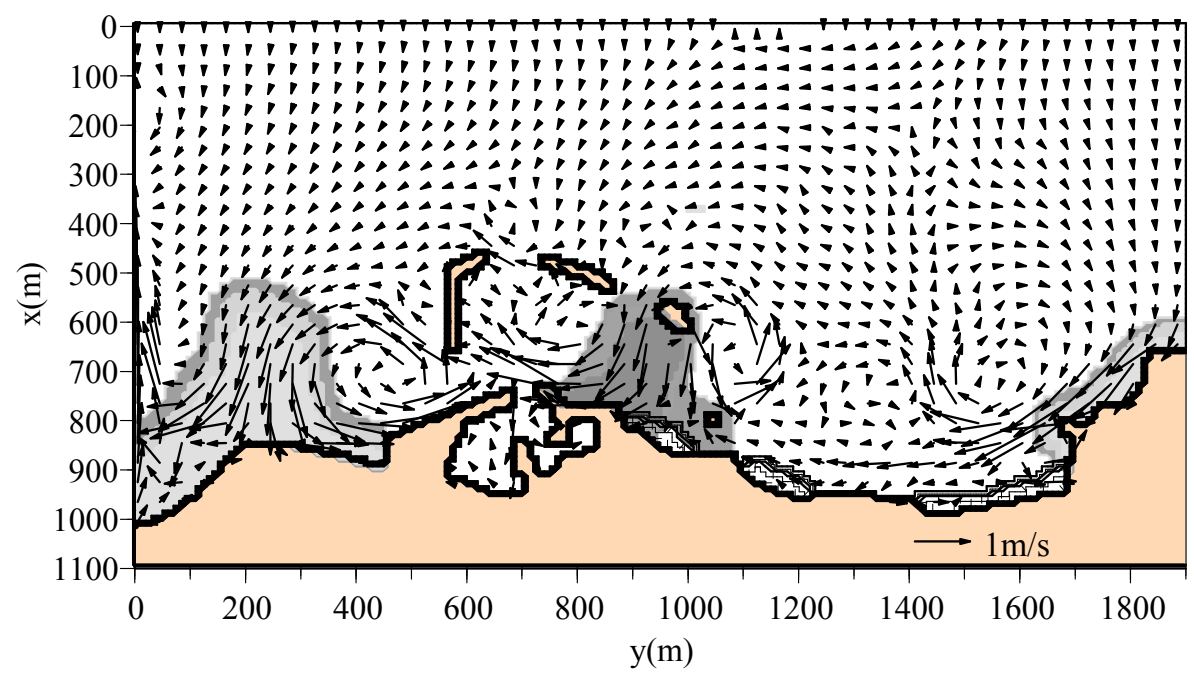

(a) Nearshore current field for step(3)(NNE)

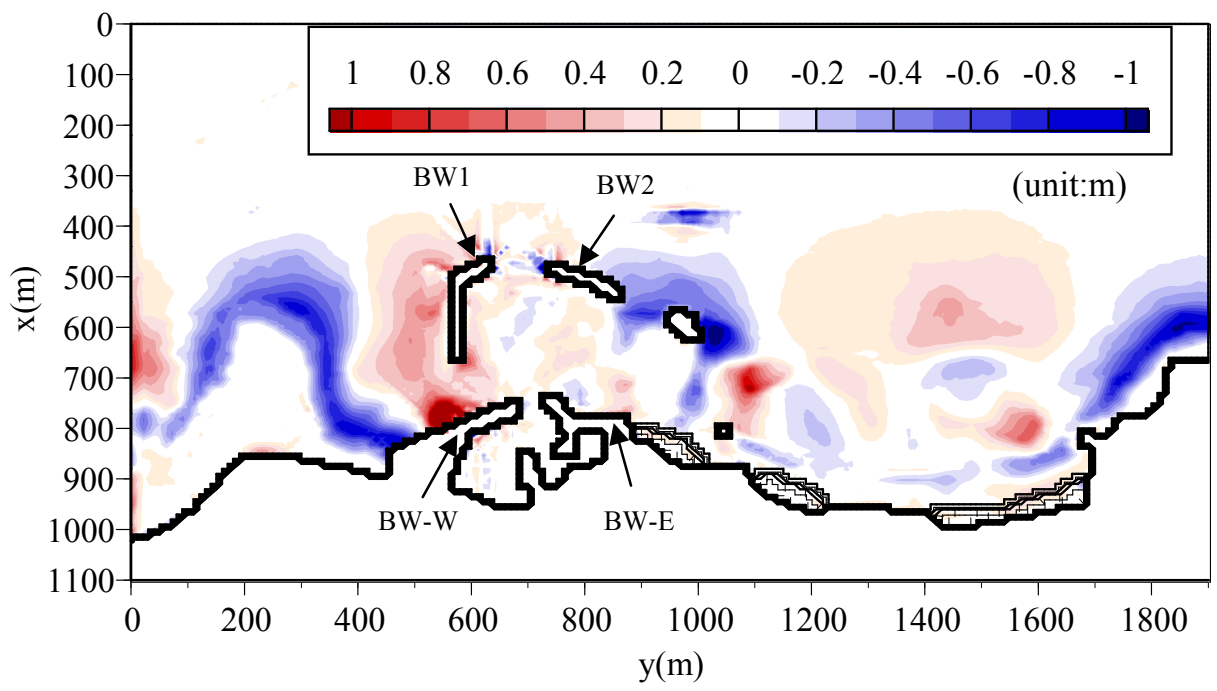

(b) Computed erosion/deposition plot

Figure 15 . Computed results for Case2

\section{CONCLUSIONS}

In this study, a numerical model for predicting 3D morphodynamics of sandy beach with shore reef area was proposed. Firstly, model tests for beach evolution of a pocket beach and a detached breakwater with exposed rock were performed. Secondly, the presented model was applied to the sounding survey results conducted at Sakenotsu fishery port in Tottori Prefecture, Japan.

From the model test, the computed results showed that the presented model could reproduce the bottom topographical changes due to the picking-up and settling of suspended sediment over the shore reef. 
From the application to the field site, it was confirmed that the computed results were qualitatively agreement with the sounding survey results in Sakanotsu fishery port.

\section{ACKNOWLEDGMENTS}

This study was supported financially by Tottori Prefectural Government Office and Tottori City Government Office.

\section{REFERENCES}

De Vriend, H.J., J. Zyserman, J. Nicholson, J.A. Roelvink, P. Pechon, and H.N. Southgate. 1993. Medium-term 2DH coastal area modeling, Coastal Engineering, 21, 193-224.

Hanson, H. and A. Militello. 2005. Representation of noerodible(Hard) bottom in Two-Dimensional Morphology two-dimensional Morphology Change and Models, US Army Corps of Engineering RDC/CHL Tec. Rep, CHETN-IV-63.

Ikeno,M, T.Shimizu, E. Kobayashi,T.Ishii and T.Saito. 2002. Application of 3-D beach deformation numerical model to a field site of sandy beach including exposed rock area around a harbor, Proceedings of 28th International Conference on Coastal Engineeing, 2994- 3006 .

Johnson,H.K., I. Broker and J.A. Zyserman. 1994. Identification of some relevant processes in coastal morphological modeling, Proceedings of $24^{\text {th }}$ International Conference on Coastal Engineering, ASCE, 2871-2885.

Kuroiwa, M., J.W. Kamphuis, T. Kuchiishi, Y. Matsubara and H. Noda. 2004. Medium-term Q-3D coastal area model with shoreline change around coastal structures, Proceedings of $29^{\text {th }}$ International Conference on Coastal Engineering, ASCE, 2194-2206.

Kuroiwa, M., T. Kuchiishi and Y. Matsubara. 2006a. Prediction System of 3D Beach Evolution with 2DH and Q3D Hydrodynamic Modes, Proceedings of $16^{\text {th }}$ International Offshore and Polar Engineering Conference, 751-757.

Kuroiwa,M., T. Kuchiishi, K. Kato and Y. Matsubara. 2006b. A quasi-three dimensional coastal are model with shoreline change for mixed-size sands, Proceedings of 30th International Conference on Coastal Engineering, ASCE,pp.3142-3154.

Kuroiwa,M.,Y. Shibutani , Y. Matsubara,T.Kuchiishi and M. Abualtyef. 2010. Numerical model of 3D morphodynamic after offshore nourishment, Proceedings of The International Conference On Coastal Engineering, No. 32, Shanghai,China. Paper \#:sediments.55. Retrieved from http://journals.tdl.org/ICCE/

Lesser, G.R., J.A. Roelvinka, J.A.T.M. van Kestera and G.S. Stelling. 2004. Development and validation of three-dimensional morphological model, Coastal Engineering, 51, 881-915.

Mase, H. 2001. Multi-directional random wave transformation model based on energy balance equation, Coastal Engineering Journal, 43, No.4, 317-337.

Sawaragi, T., Lee, J.S. and I. Deguchi. 1986. A new model for prediction of beach deformation around river mouth, Proceedings of International Symposium on Ocean Space Utilization, 85, 229-236.

Shimizu, T., A. Yamada and A. Watanabe. 1996. Coefficient and cross-shore distribution of alongshore sediment transport rate, Proceedings of Coastal Engineering, JSCE, Vo.43, 571-575. (in Japanese)

Watanabe, A., K. Maruyama, T. Shimizu and T. Sakakiyama, 1986. A numerical prediction model of three-dimensional beach deformation around a structure, Coastal Eng. in Japan, Vol.29, 179-194.

Zyserman, J.A. and H.A. Johnson. 2002. Modelling morphological processes in the vicinity of shoreparallel breakwaters, Coastal Engineering, 45, 261-284. 